\title{
Vocational education and training in Bangladesh: Why it is not working?
}

Newaz, Mohammad Tanvi $\measuredangle$

Senior Lecturer, BRAC University, Bangladesh (tanvi@bracu.ac.bd)

Faruquee, Murtaza

Graduate Student, BRAC University, Bangladesh (mfaruquee@gmail.com)

Farha, Sadia

Graduate Student, BRAC University, Bangladesh (sadia farha@hotmail.com)

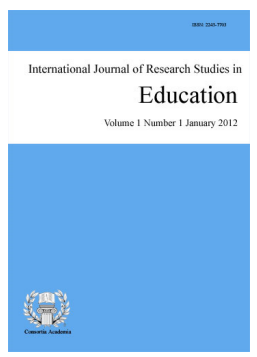

ISSN: $2243-7703$ Online ISSN: 2243-7711

OPEN ACCESS

\section{Abstract}

In order for vocational training to be successful, the successes achieved through labor market, a knowledge-based economy, the struggle against social inequality as well as the awareness of a combined and highly qualified vocational framework is required. Having all those things present to some extent in Bangladesh, the country has been suffering from lack of skilled manpower due to the poor formulation and implementation of strategies. If the country wants to achieve competitive advantage through its large workforce then there is no alternative to transform manpower into human resource by the proper implementation of vocational education and training. This article represents the current scenario of vocational education and training in Bangladesh and identifies the drawbacks of the present framework and suggests some strategies to improve the implementation of the vocational education and training programs in Bangladesh.

Keywords: training in Bangladesh; vocational education; technical education; human resource development 


\section{Vocational education and training in Bangladesh: Why it is not working?}

\section{Introduction}

Out of the labor force aged 15 years and above, around $40 \%$ have no formal education in Bangladesh. This summarizes the nature of the education and skill development task for the country. With half of the work force without education and only one-third with education at primary level and beyond, they limit the possibility of skill development through training programs and continuing upgrading and adaptation of workers to changing skill demands (SFYP, 2011). As a result, it has become a common myth that the biggest problem of the progress of Bangladesh is its huge unskilled population. But this population could be an additional advantage for the country if they can convert its people into human resource. Vocational Education and Training (VET) could be the most effective tool to develop the skill and knowledge of the people as well as it can help the nation in becoming a competent one. In today's world, the growing rate of change driven by new technology, new forms of work places, new demand for quality products and finally the shortening of the product life-cycle lead to flexible workforce and increase the role played by VET in the development of skills and competence (Attwell, 1999). Unfortunately, this area of social science is still unexplored and underdeveloped in Bangladesh. This paper identifies the problems of the present VET programs and provides some solutions to improve the scenario in Bangladesh.

The working age population (15-64) has grown by about 18 million since the mid 1990s to 2003, to 77 million and the labor force has also grown by about 10 million over the same time period (SFYP, 2011). VET can be one of the most important programs to ensure the continuous supply of skilled workforce for Bangladesh. Though Bangladesh has high demand for educated physical workforce but surprisingly this vocational education system could not meet the expectation. Compared to the students of general education, only $4 \%$ to $5 \%$ students take admission in the vocational education, and government has a plan to make it $20 \%$ by year 2020 (BTEB, 2006). In broader aspect the objective of this study is to find out why vocational education and training has not been successful in Bangladesh. The preliminary objective of this study is to analyze the current condition of vocational education in Bangladesh, mostly focusing on the curriculum and demand pattern and issues like, why young generation are not interested to study in vocational system, how the institutions are performing, and what sort of job prospects are there? Secondarily, after analyzing the current condition and future prospect of VET in Bangladesh this study will try to find some possible actions to improve the condition and make VET more useful for Bangladesh.

\section{Research methodology}

This study is based on both primary and secondary data. A focus group study was conducted to collect primary data. The focus group included 17 students from different VET institutions, 4 teachers/instructors and 3 officials from Bangladesh Technical Education Board (BTEB). Data collection has been done in three stages. First segment is related with understanding the VET structure and operation of Bangladesh Technical Education Board. Next segment is about the current condition of VET. This segment also includes information related with technical education from other parts of the world. The final segment cover information related with the future market condition for vocational education. Both qualitative and quantitative data are used in analyzing the data. Secondary data have been collected from the previous literatures and annual reports of the related departments of the government of Bangladesh.

\subsection{Limitations of the study}

Under the Bangladesh Technical Education Board (BTEB), there are various technical education programs; those are actually covering a large size of variation of level and methods. This study is only focused on the issues 
related with SSC (vocational) education system which is the first level of vocational education. Students who pass grade 8 under any method of education system in Bangladesh are allowed to get admission in SSC (vocational) program. Under this category there are 31 trades (every technical subject for SSC (vocational) curriculum is known as a 'Trade') currently available in BTEB. This study is limited in this section only.

Bangladesh Technical Education Board (BTEB) is not well organized in keeping information. Unfortunately, most of the relevant information, which are supposed to be available at BTEB were not available. BTEB printed their last annual report in 2006. After that they did not publish any report or document. However, researchers tried to extract data from other government offices and presented the most recent data. A further study with large sample size could reveal more directions for the future researchers.

\section{VET at a glance}

Vocational training and education (VET) can be defined as a link between primary vocation training and further education within a structure of lifelong learning (Rauner, 2008). It is the means whereby past and present experiences could be reconciled to the present and future workforce. The effect would be lower operating requirements through better employment of workforce capability (Attwell, 1999). It plays an exceptional role in the development of a skilled workforce as a contribution on the road to innovation and economic competitiveness. It needs to come together with industry, commerce, craft trade, trade unions, other representatives of the social partners and with other appropriate organizations and agencies for the delivery and development of the VET programs and curricula (Attwell, 1999). In order for vocational training to be successful, the successes achieved through labor market, a knowledge-based economy, the struggle against social inequality as well as the awareness of a combined and highly qualified vocational framework is required. VET and higher education, each have distinguishing missions and the stakeholders of VET include students and the community. The purpose of VET is not just to meet the needs of industry. However the way in which VET attempts to meet industry needs and the relative balance between task-focused and broader educational outcomes in VET may need to be re-evaluated (Wheelahan \& Carter, 2001).

Beside general education need for technical education at a secondary level arises based on industrialization needs. VET is influential because firstly, it appeals to numerous groups, especially in its more general forms. Secondly, it achieves support from students in hunt of jobs, businesses in looking for trained workers, politicians in explore of popular reforms that appear to deal with social and economic problems and finally educators in search of students and an important social function. Thirdly, it helps to serve several contradictory roles of education at the same time and this quality can be termed as the power of 'vocationalism'. Fourthly, it promises to reward individual students while still dealing with more combined goals like unemployment and national development and to use public resources in order to maintain combined goals while still mobilizing them for the private ends of businesses and individual students. Fifthly, it can prepare students for an increasingly distinguished set of professions while still facilitating a common core values and knowledge. Finally, it facilitates equality of opportunity through education within unequal societies where the forces to repeat inequality are even bigger (Tilak, 1988).

\subsection{VET in other countries}

VET has gifted Europe with a genuine European labor market, a knowledge based economy, reduction of social inequality as well as the realization of an integrated and highly vocation structure. The result of VET's success in Europe is that two third of the employed population has been assigned to the mid-skilled level. This involves the skilled workers and technicians (Rauner, 2008). The founding of a European system for credit transfer in vocational training- ECVET helps to use VET as a common currency Europe wide. However, in dissimilarity to higher education, the terms and conditions for the switch of trainees, trainers and teachers is seriously limited. 
The result of VET in Australia is a rigid system that is narrowly centered on work-related competencies to the elimination of broader education that makes the students response to quick changes in the economy, technology and social development. Australia has been a pioneer as well as a follower of the innovation perspective of VET. The states and territories have main responsibility for VET. The federal government contributes in VET and it uses this as a lever to control national policy. All publicly financed course delivery in the VET system must be based on training packages where they exist, and industry approved standards where they do not (Wheelahan \& Carter, 2001). VET is viewed as the solution to the educational crisis in the developing countries as well. In India, VET is provided in 9,619 schools with 21,000 sections covering approximately 1 million students. It is advised to develop vocational education to 20,000 schools and the intake capacity to 2.5 million by 2011-2012 (Goel, 2009).

\section{Present condition of VET programs in Bangladesh}

People with vocational/technical skills are in short supply, but there is evidence that there is a mismatch of jobs and skills; the difference in remuneration for skilled and unskilled workers has narrowed which is an indication that the training content and quality are not valued highly in the market. Those with training often remain unemployed or cannot find employment in their area of training - an evidence of mismatch and poor quality of training. It has been estimated that for every single person in the labor force with a technical/vocational qualification there are more than 104 others who have completed SSC or HSC; and 34 others who have gone onto a university degree or higher (SFYP, 2011).

The VET is offered at the secondary level and the target group of students is the underprivileged background. Formal VET is school based and training models often follow the colonial models. Usually students enter the vocational training track from $9^{\text {th }}$ to $12^{\text {th }}$ grade $8 \mathrm{es}$ of secondary and higher secondary education. The duration of VET ranges from three to six years, depending on the type of training provided (Alam, 2010). For the largest number of non-formal trade courses, the VET begins after eight years of schooling. However for few selected trades, it begins after secondary level. The time of training at successive stages for the national skill standard (NSS) III and II are one year each (Rafique, 1994).

There are overall 121 government institutes and 1,473 private institutes for VET. The total numbers of seats available in these institutes are 120,500 (BTEB, 2006). In 2005-2006, number of registered students in S.S.C Vocational courses was 1, 00,865 (BTEB, 2006). Out of these students, the number of students who attended exams were 47, 521 and the number of pass outs was 29, 299 (BTEB, 2006). So it shows that $61.65 \%$ of the students attending the exam passed.

The impact of public sector VET on poverty alleviation is undermined in two ways. It mainly serves the urban young males who have completed at least the eighth grade. The rural poor, who do not survive progression to grade 9, are mostly ruled out. The failure to diversify its clientele and to make the programs more flexible, adaptable and responsive to market needs and geared to the informal economy suggests that the VTE is failing to help the poor improve their employment and income opportunities (SFYP, 2011).

Most of the workers in Bangladesh are employed in the informal sector, with agriculture as the major sector of employment. The informal sector provides some 78 percent of total employment, of which 48 percent is in agriculture. Overseas employment of poorly skilled workers has also become a significant source of employment. Every year, about 500,000 Bangladeshis migrate abroad. Around 10 million people of Bangladeshi origin are living and working abroad (SFYP, 2011). Agriculture was introduced as an essential course at the secondary level as a basic element of general education from January 1994. The main areas the students study are an orientation to agriculture, horticulture, fishery and livestock. This kind of training will provide facilities for skill training through vocational education at the secondary level to about 0.7 million boys and girls. The subjects are taught initially by the field level experts (Rafique, 1994).

Within 2005-2006, there were 31 trades available in Bangladesh VET curriculum. The trades are as follows: 
dress making and tailoring, general electrical works, building maintenance, general mechanics, audio-video system, computer operation, food processing and preservation, agro based food, automotive, weaving, drafting mechanical, livestock bearing and farming, ceramics, fish culture and breeding, architectural drafting with AutoCAD, food and vegetable cultivation, poultry bearing and farming, drafting civil, dying printing and finishing, machine tool operation, welding works, civil construction, farm machinery, pluming and pipe fitting, joinery and cabinet making, electrical machine maintenance, refrigeration and air condition, electrical maintenance works, welding and fabrication, wood working and finally shrimp culture and breeding (BTEB, 2006). The private providers targets "soft" business and service sector skills like secretarial practice, dress making cookery that does not need large amount of capital outlays to deliver. However, it is recommended that few competency based curriculum in pharmaceuticals, computer literacy, IT, textiles and building construction needs to be given importance (Alam, 2010).

According to the 2005-2006 annual report of VET, if few main trades that are important for the future economy development of Bangladesh are considered, then it can be said that among the total 47, 521 students who attended VET exams, 3, 623 attended computer operation which means $7.62 \%$ students attended the exam. Although the percentage attended exam is not satisfactory, however, out of these students, $61.83 \%$ passed the exam of computer operation which can be considered as a good ratio. When it comes to weaving, 449 students attended the exam which means only $0.94 \%$ of the overall students attending VET exams participated weaving exam. Although the percentage of students attending exam is very low, however, of these, students, $72.38 \%$ passed the exam of weaving which can be considered as a good ratio. In the ceramic trade only 16 candidates attended the exam which is only $0.034 \%$ of the total students attending exam.

Out of students who attended exam, the passing rate is $43.75 \%$, not that satisfactory indeed. So this sector needs to be taken care in order for more student participation. In AutoCAD, only $0.23 \%$ of the total students attended the exam which is considered to be very poor as well. Out of the 110 attending exam, 87 passed which is $79.09 \%$ of the students attending the exam. This shows that the students attending exam actually did well. In poultry bearing and farming, only $0.59 \%$ of the overall students participated in the exam and out of those participated, $61.51 \%$ passed the exam. So this shows that the percentage of participation is low but the pass rate is satisfactory. In maintenance trade, only $0.74 \%$ of the overall VET students attended. Out of these students, only 274 passed the exam which is $77.62 \%$. This shows the pass rate is good so all that required is the student encouragement to attend the exam (appendix-2). Finally, the question of electrical maintenance works where only $0.021 \%$ of the overall students attended the exam. Out of these students, $40 \%$ passed the exam. This shows that students' participation in this trade is extremely less so this trade should be taken care of in the near future (BTEB, 2006).

\section{Table 1}

Number of institutes and students appearing SSC (vocational) examination (Begum, 2010)

\begin{tabular}{ccccc}
\hline Year & $\begin{array}{c}\text { No. of } \\
\text { Institution }\end{array}$ & $\begin{array}{c}\text { No. of Student appearing SSC } \\
\text { (vocational) }\end{array}$ & Pass rate $(\%)$ & Growth rate $(\%)$ \\
\hline 2000 & 427 & 14560 & 61.85 & - \\
2001 & 535 & 20055 & 57.16 & 37.74 \\
2002 & 680 & 25590 & 43.45 & 27.60 \\
2003 & 687 & 31627 & 38.92 & 23.59 \\
2004 & 870 & 31452 & 51.16 & -0.55 \\
2005 & 950 & 35779 & 51.44 & 13.76 \\
2006 & 1227 & 47521 & 61.65 & 35.02 \\
2007 & 1338 & 64637 & 51.08 & 33.80 \\
2008 & 1463 & 82375 & 62.88 & 27.44 \\
\hline
\end{tabular}

From 2000 to 2008 vocational education (SSC level) students have increased more than five times, and the growth rate is also averagely showing promising value, that's why from a general view this information (table-1) may become attractive. But improvement of VET may not be that good. 
Newaz, M. T., Faruqee, M., \& Farha, S.

In 2002 to 2005 surprisingly the student enrollment rate went down and then after 2006 those figures started going down again. Lack of consistency is a bigger problem than any other, because this is something which is coursed by other factors. Possible reasons could be internal or external. A further primary data study can find the real reasons of this inconsistency. Another issue is passing rate, which never went up very high from fifty percent (table-1), though some trade of SSC (vocational) shows excellent pass rate (appendix-2) but that is not the general case. Until and unless the passing rate goes high, it will be very difficult for Bangladesh to attract more students for VET.

\section{Table 2}

Comparison of general and vocational education at secondary level (Begum, 2010)

\begin{tabular}{cccc}
\hline \multirow{2}{*}{ Year } & \multicolumn{2}{c}{ SSC Examinee } & \multirow{2}{*}{ \% of Vocational Education } \\
\cline { 2 - 3 } & Total & Vocational & 2.92 \\
2003 & 1084241 & 31627 & 3.26 \\
2004 & 964507 & 31452 & 3.76 \\
2005 & 944015 & 35779 & 4.77 \\
2006 & 995123 & 47521 & 6.31 \\
2007 & 1024537 & 64637 & 8.18 \\
2008 & 1006569 & 82375 & 7.08 \\
2009 & 1058674 & 75057 & \\
\hline
\end{tabular}

Over the period of 2003 to 2009, number of students in VET (SSC level) increased, but the outcome of these numbers is not attractive at all. More than 1 million students attended SSC exam in 2009 but only 75,057 students are under vocational system (table-2), which is lower than the dropout number. Large portions of young generation are unemployed, and also a large portion of them have minimum higher secondary (HSC) level education under general system. So it is very important for Bangladesh to increase the proportion of SSC (vocational) student at least more than $25 \%$, so that local industries can have enough skilled manpower that will also reduce unemployment. Apparently, Bangladesh will get the opportunity to export skilled manpower in other developed countries.

As per approved manpower structure of education ministry, private technical institute's service rule 1996 (SRO number-54/Rule 96) dictates that only capable and experienced teachers and staffs should be recruited (BTEB, 2009). This rule is also applicable when it comes to recruiting teachers for VET of Bangladesh and no other extra rule is imposed. These teachers or trade instructors get a salary of TK 5,100-10,390 (BTEB, 2009). This rate of pay is inadequate compared to the inflation of today's economy. VET has failed to gain professional acknowledgment due to relatively low prestige and rates of pay for vocational teachers and trainers. Therefore, VET to be successful one of the ways would be to increase the salary of the trade instructors in order to motivate them to teach appropriate lesson to VET learners.

\section{Problems with the current VET programs}

The problems with the current VET program are identified from the focus group study. There are many direct and indirect problems indicated by the group members. Some of the major issues are given below.

$>$ Curriculum: The curriculum of VET has not been updated for long time. There is no synergy between the market demand and programs offered in the VET institutions. Employers' perception is that the products from the vocational system are not meeting their needs; that the system continues to produce graduates for old and marginal trades, which have no market demand, while skill needs for newer trades remain unmet.

$>$ People do not have proper awareness about VET: Now this is more like a combination of some other very relevant barriers (which will come by following points). As a result, lack of awareness about the any issues regarding VET are very alarming barrier for developing this sector. 
D Job Market: In Bangladesh related with education the very first thing strike in peoples' mind is, 'what sort of job I will get after finishing the education?' In a country where so many people live below poverty line, this is not a surprising question. All booming industries have a need of skilled young workforce. On the other hand, most of the young people believe there will be no job for them if they go for SSC (vocational). A group of people also think that going for VET is actually narrowing down their opportunities; they think they will have a large panel of choice if they go for general education.

> Social acceptance: Two social dilemmas are causing this problem. One is, only 'weak student' can go for vocational education. People have mindset that VET students are not intelligent enough to continue general education. Other one is that after having done vocational education, they will not get enough social respect, because their opportunities will be very limited.

$>$ Cost of VET: There is another group of people who believe that the cost of attending vocational education is higher than the general education. The common people of Bangladesh are fighting to provide education to their children. A little increase in education cost makes them afraid about their future. So this cost issue creates a strong barrier for VET.

$>$ Shortage of skilled instructors: Vocational education is not an education for achieving certificates; on hand training is a big part of it. When student do not find efficient instructor in their institutions then they lose interest in VET. Even those students have passed out from SSC (vocational) they are also not well trained. Both of these problems are created because of inefficient teachers.

Policy: When efficiency is an issue for teachers then the considerable factor is that efficient and well educated people are not interested in the job of VET instructor. Salary and other benefits are not updated as well as not attractive to those teachers. There are thousands of VET institutions spread over the country so there should be many jobs available. But in reality it is different.

\subsection{Recommendations}

If Bangladesh wants to consider its human capital as an asset, VET sector has to be considered as an industry, which develops the strong human capital to boost Bangladesh's economy. BTEB could use some 'Banding', yes that's the right word to pin point the exact recommendation. BTEB is a government's regulator to supervise VET issues, so if they go for setting direct communication with the mass people then that will have a strong positive effect on students' enrolment. It will work in three ways- first, when information will come from government's source then people will have strong reason to believe that (they could follow the concept 'legal emigration' promotion of Bangladesh government). BETB, ministry of education and ministry of labor can jointly arrange radio, television and billboard promotion. Another very effective program could be arranging road show in rural areas at every December for those students who just passed grade 8 . Second, the private institutions will not be able to miss represent the truth to bluff, and finally once BTEB can earn a prestigious brand value then social acceptance of VET will be high and young people will be more interested to study under this system. So it is very clear that how one small effort can bring so many strong outcomes.

VET needs a strong 'communication hub', it can work either way BTEB could set a central communication hub or they could motivate VET institutions to set separate hub. Now this hub will be responsible to create communication channel between the pass out students and possible organization who could hire them, even BTEB can set a separate wing to ensure smooth emigration of those VET students'. As soon as students have the career certainty, they will be more comfortable with VET.

Some specific recommendations are given considering three perspectives: curriculum, student and teacher.

Curriculum: Though a number of experts and experienced people set these curriculums (trades) for the SSC (vocational) program, but a number of changes should be made to make it more effective. 
$>$ Out of current 31 trades only few are very relevant for next 10 years. So curriculum of those trades need regular review to ensure that students are receiving update knowledge about the relevant technology. BTEB should conduct a need assessment study to find out more future demand based trades and dropped some backdated trades.

D Every trade needs some addition as its basic course. It is not necessary to be main text that could be some long (like 3 months program) training. As this SSC (vocational) students are entering in a work place at very early age so training on organization culture adoption could be very necessary for them. Even for those students who are interested in emigration, training on foreign culture and foreign language can be very helpful for them, and this program can be designed on only those countries (separately) which will be prospect full market for Bangladesh.

The pass rate in SSC vocational (table-1) is near half of examinee, which is lower than the general SSC, so a review on the teaching pattern and syllabus is necessary to find what are the issues that causes lower pass rate, because, until and unless the pass rate increase it will be very difficult to obtain students attention.

Student: This is the segment which is most difficult portion for bringing any change, because this segment is very heterogeneous in terms of making education decision, though they have one issue is very common that is career prospect, so some action could be taken based on that aspect.

$>$ BTEB should spread the message among students that these sorts of technical educations have more job opportunities compared to general education. Most of the physical labor related jobs are based on some technical knowledge not general theoretical education. Once student get proper understanding on this face they will be interested in VET, and the branding program will also be a good way to create this awareness.

$>$ Create an understanding among students that, cost (mostly for private tuition) of general education (science, business studies or arts) is higher than the vocational education, because these vocational subjects are based on practical on hand lab activity, therefore necessity of private tuition is very low for the vocational students. Again if the promotional initiative can create this environment then attracting more talented students for vocational program will be easier.

$>$ Apprenticeship programs should be encouraged to ensure the students have more practical exposures from various industries.

Teacher: It would be unfair to expect having highly skilled vocational student without improving the condition of trade instructors. This is easily understandable that without skilled instructors all other initiatives will be useless.

$>$ VET institutions will not be able to attract skilled teachers until they give proper value to their job. There must be some improvement in current trade instructors' salary scale (appendix-1), people who are efficient on their job trade they can find high paid job in any industry so to have those in academic field, remuneration should be at least equal to other industries.

$>$ Training programs should be conducted to improve the quality of the current teachers of vocational trades. Industry experts should be brought to encourage both students and instructors and that will help to build a relationship between graduates and employers. Some general education institutions have vocational trades also, so management of those institutions has to be concern for trade instructors.

$>$ Exchange programs can be arranged with different developed countries in order to give instructors more contemporary knowledge. 


\section{Conclusion:}

Knowledgeable and skilled workforce is one of those assets which is neither get depreciated nor diminished as long as they are developed efficiently. As a result, developing this asset will ensure higher economic progress for Bangladesh. Now, making all these changes at a time would be difficult but responsible authorities should start progressing with positive attitude and optimistic mind set. The government should aim to meet the needs of employers, individuals and the nation and push the economy from its low-skilled equilibrium while redesigning VET programs. They should promote social cohesion and inclusion through equal access to decent employment. Apparently, in order to achieve competitive advantage through people, there is no other alternative than developing the skill of general people. Redesigning vocational education and training (VET) programs could be the first step of this road of success.

\section{References:}

Alam, G. M. (2010). A proper plan needed in place for upcoming technical, vocational, education projects. Journal of University of Malaya, 2(3), 72-83.

Alam, G. M. (2009). Vocational training and linkage with income. Journal of ILO office in Bangladesh, 1(3), 167-179.

Attwell, G. (1999). New roles for vocational education and training teachers and trainers in Europe: A new framework for their education. Industrial and Commercial Training, 31(5), 190-200. http://dx.doi.org/10.1108/00197859910284782

Begum, R. (2010). Re-orienting TVET Policy towards education for sustainable development: Bangladesh Perspective. Ministry of education (Bangladesh) report.

BTEB. (2006). BTEB annual report (2005-06). Bangladesh technical education board report.

BTEB. (2009). Guide book of vocational education system. Bangladesh technical education board report.

Falk, I. (2003). Designing effective leadership interventions: A case study of vocational education and training. Leadership \& Organization Development Journal, 24(4) 193-203. http://dx.doi.org/10.1108/01437730310478066

Goel, D. V. (2009). Technical and vocational education and training (TVET) system in India for sustainable development. Ministry of human resource development report.

Kay, C., Fonda, N., \& Hayes, C. (1998). Growing an innovation workforce: a new approach to education and training. Education + Training, 40(6/7), 267-275. http://dx.doi.org/10.1108/00400919810234054

Matlay, H. (2001). Entrepreneurial and vocational education and training in central and Eastern Europe. Education + Training, 43(8/9), 395 - 404

Rafique, A. (1994). The development of technical and vocational education in Bangladesh--A case study in quality improvement. Case studies on technical and vocational education in Asia and the Pacific. RMIT Report for UNESCO.

Rauner, F. (2008). European vocational education and training: A prerequisite for mobility? Journal of European Industrial Training, 32, 85-98. http://dx.doi.org/10.1108/03090590810861640

SFYP. (2011). Sixth Five Year Plan FY 2011 - 2015, Ministry of Planning Report.

Tilak, J. B. (1988). Vocational Education in South Asia: Problems and Prospects. International Review of Education, 34, 244-257. http://dx.doi.org/10.1007/BF01874549

Wheelahan, L., \& Carter, R. (2001). National training packages: a new curriculum framework for vocational education and training in Australia. Education + Training, 43(6), 303-316.

http://dx.doi.org/10.1108/EUM0000000005755 


\section{Appendix 1}

Required post and wage scale for every trade

\begin{tabular}{cccc}
\hline Serial & Name of post & No. of post & wage scale \\
\hline 1 & Trade instructor & 2 (per trade) & $5100-10390 /-$ \\
2 & Shop/ lab assistant & 1 (per trade) total 2 person & $2600-4870 /-$ \\
\hline Source: BTEB. (2009). Guide book of vocational education system of BTEB
\end{tabular}

Source: BTEB. (2009). Guide book of vocational education system of BTEB.

\section{Appendix 2}

Statistic of SSC (vocational) final exam-06

\begin{tabular}{|c|c|c|c|c|}
\hline Serial & Trade & $\begin{array}{c}\text { Student } \\
\text { attempted }\end{array}$ & $\begin{array}{c}\text { Student } \\
\text { passed out }\end{array}$ & $\begin{array}{l}\text { Passed out } \\
\text { ratio }\end{array}$ \\
\hline 1 & Dress making and tailoring & 8755 & 5437 & $62.10 \%$ \\
\hline 2 & General electrical works & 9535 & 5943 & $62.33 \%$ \\
\hline 3 & Building maintenance & 5772 & 3462 & $59.98 \%$ \\
\hline 4 & General mechanics & 5398 & 3220 & $59.65 \%$ \\
\hline 5 & Audio video system & 224 & 145 & $64.73 \%$ \\
\hline 6 & Computer operation & 3623 & 2240 & $61.83 \%$ \\
\hline 7 & Food processing and preservation & 2612 & 1552 & $59.42 \%$ \\
\hline 8 & Agro based food & 3429 & 2026 & $59.08 \%$ \\
\hline 9 & Automotive & 978 & 598 & $61.15 \%$ \\
\hline 10 & Waiving & 449 & 325 & $72.38 \%$ \\
\hline 11 & Drafting mechanical & 130 & 97 & $74.62 \%$ \\
\hline 12 & Livestock bearing and farming & 34 & 21 & $61.76 \%$ \\
\hline 13 & Ceramic & 16 & 07 & $43.75 \%$ \\
\hline 14 & Fish culture and breeding & 133 & 87 & $65.41 \%$ \\
\hline 15 & Architectural drafting with AutoCAD & 110 & 87 & $79.09 \%$ \\
\hline 16 & Fruit and vegetable cultivation & 210 & 133 & $63.33 \%$ \\
\hline 17 & Poultry bearing and farming & 278 & 171 & $61.51 \%$ \\
\hline 18 & Drafting civil & 350 & 213 & $60.86 \%$ \\
\hline 19 & Dying printing and finishing & 502 & 409 & $81.47 \%$ \\
\hline 20 & Machine tool operation & 523 & 356 & $68.07 \%$ \\
\hline 21 & Welding works & 752 & 398 & $52.93 \%$ \\
\hline 22 & Civil constriction & 1178 & 684 & $58.06 \%$ \\
\hline 23 & Farm machinery & 832 & 545 & $65.50 \%$ \\
\hline 24 & Plumbing and pipe fittings & 103 & 56 & $54.37 \%$ \\
\hline 25 & Joinery and cabinet making & 16 & 11 & $68.75 \%$ \\
\hline 26 & Electrical machine maintenance & 353 & 274 & $77.62 \%$ \\
\hline 27 & Refrigeration and air-condition & 825 & 553 & $67.03 \%$ \\
\hline 28 & Electrical maintenance works & 10 & 4 & $40.00 \%$ \\
\hline 29 & Welding and fabrication & 113 & 72 & $63.72 \%$ \\
\hline 30 & Wood working & 252 & 158 & $62.70 \%$ \\
\hline \multirow[t]{2}{*}{31} & Shrimp culture and breading & 26 & 15 & $57.69 \%$ \\
\hline & Total & 47521 & 29299 & $61.65 \%$ \\
\hline
\end{tabular}




\section{Appendix 3}

Statistics of SSC (vocational) institutions

\begin{tabular}{|c|c|c|c|c|c|}
\hline \multirow{2}{*}{ Serial } & \multirow{2}{*}{ Segments } & \multicolumn{2}{|c|}{ Number of institutions } & \multirow{2}{*}{ Total } & \multirow{2}{*}{$\begin{array}{c}\text { Total } \\
\text { sets }\end{array}$} \\
\hline & & Government & Private & & \\
\hline 1 & SSC (vocational) & 64 & 1473 & 1537 & 111900 \\
\hline 2 & SSC (vocational) TTC & 17 & - & 17 & 5000 \\
\hline \multirow[t]{2}{*}{3} & SSC (vocational) textile & 40 & - & 40 & 3600 \\
\hline & Total & 121 & 1473 & 1594 & 120500 \\
\hline
\end{tabular}

Source: BTEB. (2006). BTEB annual report. 
Newaz, M. T., Faruqee, M., \& Farha, S. 